\title{
Relationship between Sporulation Medium and Germination Ability of Mucor racemosus Sporangiospores
}

\author{
By MATTHEW L. TRIPP ${ }^{1}$ AND JOHN L. PAZNOKAS 1,2* \\ Departments of Bacteriology and Public Health ${ }^{1}$ and Basic Medical Sciences ${ }^{2}$, Washington \\ State University, Pullman, Washington 99164, U.S.A.
}

(Received 17 December 1980; revised 22 March 1981)

\begin{abstract}
Asexual sporangiospores of Mucor racemosus produced on a minimal sporulation medium (M-spores) germinated only if glucose, mannose or a complex substrate such as peptone, yeast extract or Casamino acids was present. Once germinated, growth was supported by a wide range of substrates including amino acids, carbohydrates or organic acids. Sporangiospores produced on a nutritionally complex sporulation medium (C-spores) germinated on a wide range of carbon sources. C-spore phenotype was pleiotropic in that sporangiospores capable of germinating on cellobiose could always germinate on glutamate or xylose; but C-spores capable of germinating on xylose or glutamate did not always germinate on cellobiose. There was a hierarchy of substrates capable of initiating germination with glucose $=$ mannose $>$ xylose $>$ glutamate $>$ cellobiose. C-spores also differed from $\mathbf{M}$-spores by initiating germination in the presence of the non-metabolizable glucose analogue 3$O$-methylglucose. These results suggest that at least two sporangiospore phenotypes are produced depending upon the concentration and type of ingredients present in the sporulation medium.
\end{abstract}

\section{INTRODUCTION}

The dimorphic phycomycete Mucor racemosus has been employed as a model system to study the control mechanisms involved during the yeast to hyphal differentiation process. The success of these studies resides in the fact that a single, controllable change in culture conditions leads to a predictable and synchronous morphological transition (Bartnicki-Garcia \& Nickerson, 1962; Bartnicki-Garcia, 1968; Schulz et al., 1974). Anaerobically, under $\mathrm{CO}_{2}$ or with a high flow rate of $100 \%$ nitrogen (Mooney \& Sypherd, 1976), vegetative growth occurs as budding yeast: low flow rates of nitrogen results in mycelial growth. A fermentable hexose is required for anaerobic growth of both forms (Larsen \& Sypherd, 1974).

Aerobically, growth occurs as hyphae and is supported by a wide range of substrates including carbohydrates, amino acids and organic acids (Bartnicki-Garcia \& Nickerson, 1962). On solid medium, mycelia form aerial hyphae which differentiate into sporangiophores. By 3-5 d the sporangiophores appear dark and contain mature, asexual sporangiospores. These sporangiospores remain dormant when harvested and held in distilled water; however, when placed into a suitable nutrient medium they undergo a morphological transition, initiate germination and develop from an elliptical sporangiospore into a spherical vegetative cell prior to either germ tube or bud emergence. This series of morphological events is amenable to biochemical analysis.

The components necessary for the initiation of germination have been reported to be present in many fungal spores. However, the mechanism by which the dormant state is maintained is unknown. 
Most biochemical studies of Mucor described previously have been carried out in a nutritionally complex medium. We have initiated studies employing the defined minimal medium of Peters \& Sypherd (1978) to determine the chemical requirements for sporangiospore germination. These studies led to the observation that the ability to germinate and the rate of germination of $\boldsymbol{M}$. racemosus sporangiospores on a given carbon source is directly related to the nutritional complexity of the sporulation medium.

\section{METHODS}

Organism and culture conditions. Mucor racemosus (M. lusitanicus) ATCC 1216B was used in all experiments. Asexual sporangiospores were produced primarily on two types of media. Sporangiospores designated C-spores were produced on a complex sporulation medium (CSM) consisting of 1\% (w/v) peptone (Difco lot no. 54219

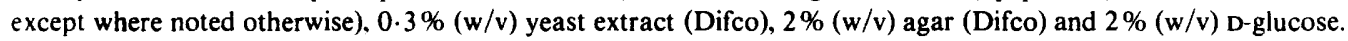
Sporangiospores designated $\mathbf{M}$-spores were produced on a minimal sporulation medium (MSM) consisting of $0.05 \%(\mathrm{w} / \mathrm{v})$ yeast nitrogen base without amino acids (Difco), $10 \mathrm{mM}-\left(\mathrm{NH}_{4}\right)_{2} \mathrm{SO}_{4}, 10 \mathrm{mM}-\mathrm{L}$-glutamate, $2 \%(\mathrm{w} / \mathrm{v})$ agar (Difco) and $2 \%(\mathrm{w} / \mathrm{v})$ D-glucose. The minimal germination medium (MGM) was a modified MSM in which L-glutamate, agar and glucose were omitted. The various carbon sources were reagent grade (Sigma) and usually supplied in MGM at $100 \mathrm{mM}$, a concentration giving the optimum germination rate, except the disaccharides which were supplied at $50 \mathrm{~mm}$. The $\mathrm{pH}$ of all media was adjusted to 5.0 with $\mathrm{H}_{2} \mathrm{SO}_{4}$.

The sporulation media were spread-inoculated with $0.05 \mathrm{ml}$ of a stationary phase culture of yeast (growing in $0.3 \%$ yeast extract, $1 \%$ peptone, $1 \%$ glucose, under $100 \% \mathrm{CO}_{2}$ ) and incubated at $22{ }^{\circ} \mathrm{C}$. Sporangiospores were harvested $5 \mathrm{~d}$ after inoculation, washed twice in distilled water, and counted with either a haemocytometer or a Coulter counter (sporangiospores from 3, 4, 5, 6 and $7 \mathrm{~d}$ plates all had similar germination ability). Portions $(10 \mathrm{ml})$ of $\mathrm{MGM}$ contained in $50 \mathrm{ml}$ flasks were inoculated to a final concentration of $1 \times 10^{6}$ sporangiospores $\mathrm{ml}^{-1}$ (inocula of $10^{4}, 10^{5}, 5 \times 10^{5}, 10^{6}$ and $2 \times 10^{6}$ sporangiospores $\mathrm{ml}^{-1}$ germinated at essentially identical rates, whereas inocula of $10^{7}, 2 \times 10^{7}$ and $10^{8}$ sporangiospores $\mathrm{ml}^{-1}$ germinated at decreasing rates) and incubated at $25^{\circ} \mathrm{C}$ in a gyrorotatory water bath incubator shaking at $150 \mathrm{rev}$. $\mathrm{min}^{-1}$. All sugars were autoclaved separately from the sporulation medium and added aseptically. Freshly prepared solutions of sugars were routinely added to the minimal germination test medium (MGM) unsterile to eliminate degradation. Identical results were obtained with carbohydrates sterilized by filtration.

Chemicals. The non-metabolizable glucose analogue 3- $O$-methyl-D-glucose was routinely used at $20 \mathrm{~mm}$. Adenosine $3^{\prime}: 5^{\prime}$ cyclic monophosphate (cyclic AMP) was used at $10 \mathrm{mM}$. Both were reagent grade and supplied by Sigma.

Analysis of germination. Mucor racemosus sporangiospore germination involves a swelling phase prior to germ tube emergence. Coulter counter analysis has been reported to be the method of choice for the analysis of spore swelling (Barnes et al., 1966; Barnes \& Parker, 1967; Mandels \& Darby, 1953; Mandels, 1965). In these studies, the swelling phase was monitored by measuring sporangiospore volume at various time intervals with a Coulter counter (model ZB1) coupled to a 100-channel pulse-height analyser (Channelyzer) and an XY plotter. The aperture tube employed throughout this study was $100 \mu \mathrm{m}$. Routinely, a sample of the germination mixture was diluted in Isoton (Coulter Electronics, Hialeah, Florida, U.S.A.), a counting fluid which both dispersed the sporangiospores and stopped the swelling process. (Mucor racemosus cells placed in Isoton stop developing immediately and remain at the volume attained at the time they were placed in the Isoton solution for at least $24 \mathrm{~h}$.) For each time point, 8000-15000 sporangiospores were counted and sized. The average volume of synchronously germinating sporangiospore populations was calculated from the XY plots. Monosized polystyrene beads $(72 \cdot 25$ and $20.10 \mathrm{\mu m}^{3}$; obtained from Coulter Electronics) were used as described by the manufacturer to calibrate the Coulter counter. An external check on the calibration was made by microscopic measurements of the beads and the sporangiospores. The volumes determined by both methods were essentially identical. The proportion of the sporangiospore population swelling from 20 to $>45 \mu \mathrm{m}^{3}$ was recorded from the integrator and is reported as the percentage of the sporangiospore population initiating germination. This allowed monitoring of asynchronously germinating sporangiospore populations.

\section{RESULTS}

\section{Size distribution of $M$ - and $C$-spores during germination}

Mucor racemosus sporangiospores produced on either complex (C-spores) or minimal (M-spores) sporulation medium were found by Coulter sizing analysis to be similar in size ranging from 15 to $60 \mu \mathrm{m}^{3}$, with the major portion averaging $20 \mu \mathrm{m}^{3}$ when harvested in 


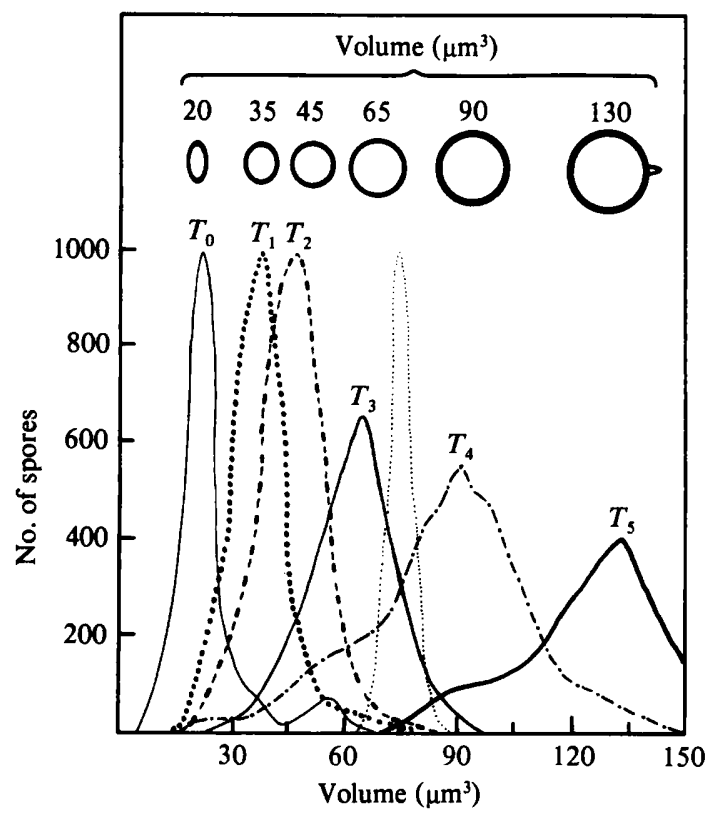

Fig. 1

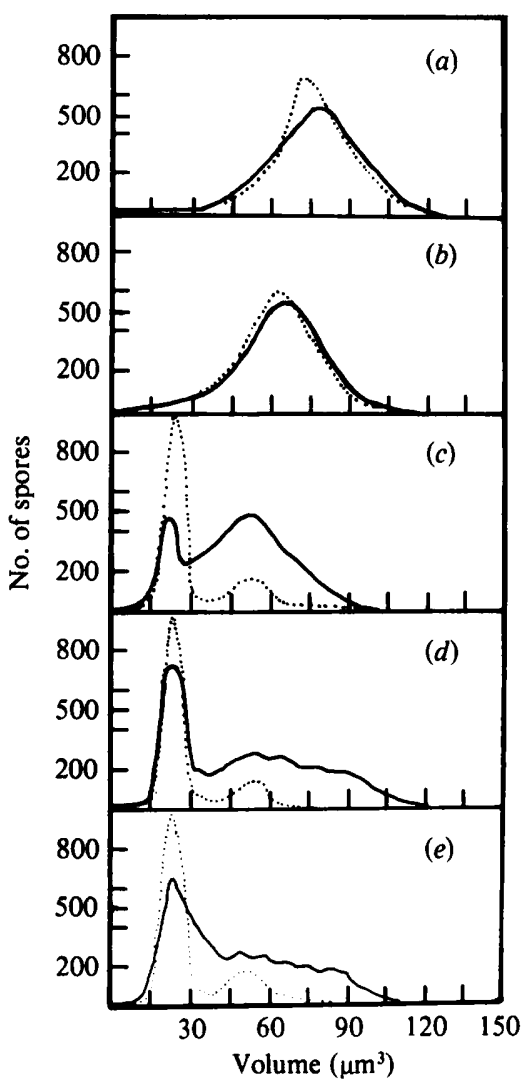

Fig. 2

Fig. 1. Germination of M-spores of $M$. racemosus in MGM/glucose (100 mM) was monitored at $1 \mathrm{~h}$ intervals $\left(T_{0}, T_{1}, T_{2}\right.$ etc.) by measuring the size distribution of the swelling sporangiospores by Coulter sizing analysis. Monosized polystyrene beads $\left(72.25 \mu \mathrm{m}^{3}\right)$ were used as a sizing standard (unlabelled peak).

Fig. 2. Typical Coulter plots depicting the size distribution for M-spores (...) and C-spores ( $\longrightarrow$ ) after $4 \mathrm{~h}$ incubation in MGM containing $100 \mathrm{mM}$ of one of the following single substrates: $(a)$ glucose, $(b)$ mannose, $(c)$ xylose, $(d)$ maltose or $(e)$ glutamate.

distilled water. This range is represented by a typical Coulter plot of the zero-time $\left(T_{0}\right)$ sample shown in Fig. 1. The sporangiospores remained at this volume for several days in the absence of a suitable carbon source. The addition of $100 \mathrm{mM}$-glucose to the MGM resulted in a rapid increase in volume with the elliptical sporangiospores taking on a spherical appearance after $1 \mathrm{~h}$ accompanied by an increase in volume from 20 to about $35 \mu \mathrm{m}^{3}$. The swelling rate was determined by monitoring the mode volume of the sporangiospore population with time. Figure 1 represents a series of Coulter tracings made at $1 \mathrm{~h}$ intervals from a typical experiment where $\mathrm{M}$-spores were placed into MGM containing $100 \mathrm{mM}$-glucose as the sole carbon source. Only after the sporangiospores had swollen to $130 \mu \mathrm{m}^{3}$ (Fig. 1) were germ tubes observed microscopically. By plotting the log of the average sporangiospore volume (as determined by the mode of each curve) against time, a straight line relationship was found (Fig. $3, r=>0.99$ for any given experiment). The results from several experiments indicated that the swelling rate for $\mathrm{C}$-spores (slope 0.1502 ) was slightly greater than that for $\mathrm{M}$-spores (slope 0.1447 ) germinating on glucose at the same concentration. This swelling phase (from 20 to $130 \mu \mathrm{m}^{3}$ ) prior to germ tube emergence was considered to be the germination phase. 


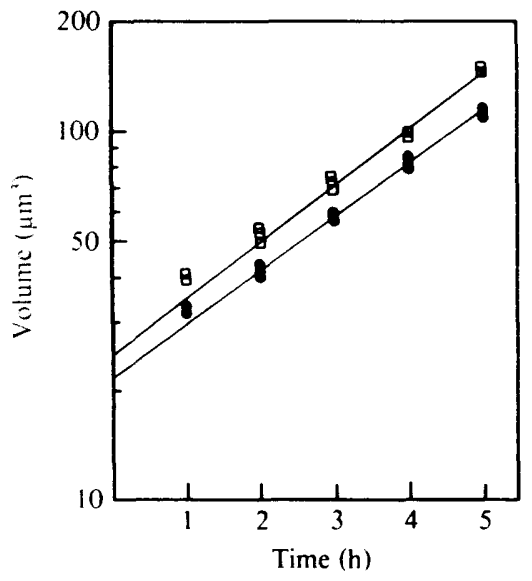

Fig. 3

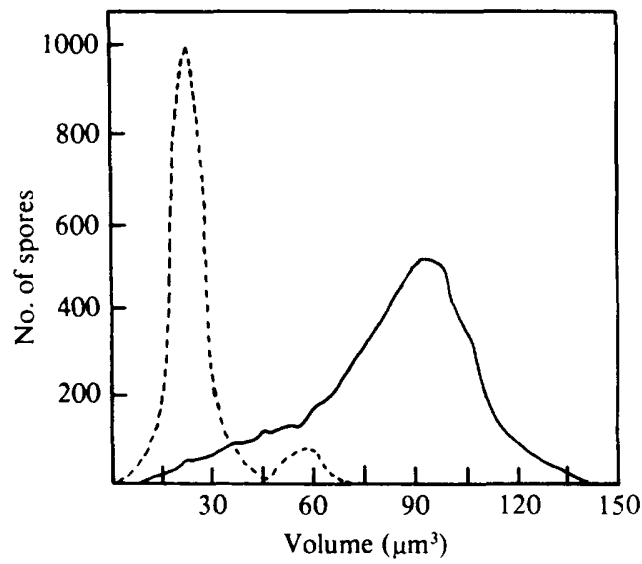

Fig. 4

Fig. 3. Typical plot of log sporangiospore volume against time for C-spores ( $\square$ ) and M-spores (O) germinating in $\mathrm{MGM} / \mathrm{glucose}(100 \mathrm{mM})$. Each point represents the average of two replicates per experiment. $T_{130}$ (i.e. the time for the average population to swell to $130 \mu \mathrm{m}^{3}$ ) was calculated from the lines to be $5.3 \mathrm{~h}$ for $\mathrm{M}$-spores and $4.8 \mathrm{~h}$ for $\mathrm{C}$-spores.

Fig. 4. Typical Coulter plots of the size distribution for M-spores (-- ) and C-spores (- $\longrightarrow$ after $24 \mathrm{~h}$ incubation in MGM containing 3-O-methylglucose $(20 \mathrm{~mm})$ in the absence of an exogenous energy source. The $\mathbf{M}$-spore population microscopically appeared elliptical, ungerminated and identical to the MGM control (no substrate). The C-spore population upon developing to about $90 \mu \mathrm{m}^{3}$ stopped short of germ tube emergence.

Hence, the time for the average sporangiospore population to swell to $130 \mu \mathrm{m}^{3}$, denoted $T_{130}$, is analogous to the time it takes the average sporangiospore in a given population to germinate. Thus, the germination rate of sporangiospores produced on various sporulation media can be easily compared. The $T_{130}$ for $\mathrm{C}$-spores $(4.8 \mathrm{~h})$ was consistently lower than that for M-spores $(5 \cdot 3 \mathrm{~h})$.

\section{Analysis of germination synchrony}

Mucor racemosus C-spore germination was asynchronous in MGM containing a non-hexose such as glutamate as the sole carbon source (Fig. $2 e$ ). Hence, it was not possible to analyse germination by monitoring the movement of a single peak representing the entire sporangiospore population. Instead, germination was analysed by monitoring the proportion of the sporangiospores which initiated germination and swelling to some arbitrary size, i.e. $45 \mathrm{\mu m}^{3}$. Sporangiospores which initiated germination in the presence of a suitable carbon source and swelled to $45 \mu \mathrm{m}^{3}$ continued to germinate if left in the same medium. The Coulter integrator allowed determination of the number of sporangiospores present within a given size range. Since $90 \%$ of the sporangiospore population ranged from 0 to $45 \mu \mathrm{m}^{3}$ in the absence of a suitable germinant, that proportion of the sporangiospore population which swelled to $>45 \mu \mathrm{m}^{3}$ was operationally defined as having initiated germination. It should be stressed that this is only an operational definition. The proportion of the sporangiospore population larger than $45 \mu \mathrm{m}^{3}$ at time zero varied from about 5 to $15 \%$ and has been subtracted (corrected) from all readings in order to make comparisons between sporangiospore preparations.

\section{Effect of sporulation media on sporangiospore germination}

Sporangiospores produced on complex sporulation medium (C-spores) were compared with sporangiospores produced on a minimal sporulation medium (M-spores) with respect to their ability to initiate germination on a variety of carbon sources. Both $\mathrm{C}$ - and $\mathbf{M}$-spores 
Table 1. Germination ability of $M$ - and $C$-spores on various carbon sources

Sole carbon source in MGM

Glucose $(100 \mathrm{~mm})$
Mannose $(100 \mathrm{~mm})$
Xylose $(100 \mathrm{~mm})$
Arabinose $(100 \mathrm{~mm})$
Cellobiose $(50 \mathrm{mM})$
Maltose $(50 \mathrm{~mm})$
Glutamate $(100 \mathrm{mM})$
L-Alanine $(100 \mathrm{~mm})$
Difco peptone $(1 \%)$
Difco yeast extract $(1 \%)$
Casamino acids, vitamin-free $(1 \%)$
No carbon source - control

\begin{tabular}{cc} 
Percentage of spores & $>45 \mu^{3}$ by $8 \mathrm{~h}$ \\
\hline M-spores* & C-spores $\dagger$ \\
$>95$ & $>95$ \\
$>95$ & $>95$ \\
$<5$ & $70(63-76)$ \\
$<5$ & $18(18-26)$ \\
$<5$ & $24(15-45)$ \\
$<5$ & $35(21-45)$ \\
$<5$ & $54(47-78)$ \\
$<5$ & $18(18-28)$ \\
$>95$ & $>95$ \\
$>95$ & $>95$ \\
$>95$ & $>95$ \\
$<5$ & $<5$
\end{tabular}

* Typical results.

† Data obtained for a single batch: values in parentheses show the range obtained for several separate batches.

Table 2. Differential effects of 3-O-methyl-D-glucose and cyclic AMP on sporangiospore germination

Addition(s) to MGM*
3-O-Methylglucose (no carbon source)
3-O-Methylglucose + glutamate
Glucose
Glucose + glutamate
Cyclic AMP (no carbon source)
Cyclic AMP + glutamate
Glutamate

\begin{tabular}{|c|c|}
\hline M-spores & C-spores \\
\hline$<5$ & $69(4.0) \dagger$ \\
\hline$>95(4.3) \dagger$ & $>95(3.0)$ \\
\hline$>95(2.7)$ & $>95(2.4)$ \\
\hline$>95(2.4)$ & $>95(2 \cdot 1)$ \\
\hline$<5$ & $<5$ \\
\hline$<5$ & $76(2.7)$ \\
\hline$<5$ & $74(4 \cdot 0)$ \\
\hline
\end{tabular}

* Concentrations: 3-O-methylglucose, $10 \mathrm{mM}$; glutamate, $100 \mathrm{mM}$; glucose, $10 \mathrm{~mm}$; cyclic AMP, $10 \mathrm{mM}$.

$+T_{G S O}$, i.e. calculated (linear regression analysis) time in hours for $50 \%$ of a sporangiospore population to swell from 20 to $>45 \mu \mathrm{m}^{3}$.

germinated synchronously on glucose or mannose (Fig. $2 a, b)$. A variable proportion of $\mathrm{C}$-spores germinated asynchronously on xylose, maltose or glutamate (Fig. $2 c, d, e$ ); in contrast, none of the $\mathbf{M}$-spores germinated on the three non-hexoses. The percentage of each $C$ - and M-spore population initiating germination and swelling to greater than $45 \mu \mathrm{m}^{3}$ by $8 \mathrm{~h}$ on a variety of substrates is given in Table 1 . After $24 \mathrm{~h}$ incubation, little or no growth was observed in culture flasks containing $M$-spores and a non-hexose; and upon microscopic examination only elliptical, ungerminated sporangiospores could be seen with the exception of an occasional mycelial micro-colony. The contents of the flasks containing MGM/cellobiose and MGM/glutamate were filtered through Whatman no. 1 filter paper to remove germinated cells and then recounted. Essentially all the M-spores could be accounted for, and averaged $20 \mathrm{\mu m}^{3}$. The variation from experiment to experiment in the ability of C-spores to germinate on non-hexoses is indicated in Table 1 . This variability was between $\mathrm{C}$-spore preparations and not experimental error within an experiment (usually $<5 \%$ between replicates).

\section{Differential effects of 3-O-methylglucose and cyclic AMP on sporangiospore germination}

It was found that the non-metabolizable glucose analogue 3-O-methylglucose would initiate swelling of $\mathbf{C}$-spores but not $\mathbf{M}$-spores in a defined medium without an exogenous carbon 
Table 3. Effect of complex components of the sporulation medium on sporangiospore germination ability

\begin{tabular}{|c|c|c|c|c|c|}
\hline \multirow[b]{2}{*}{$\begin{array}{l}\text { Basic } \\
\text { sporulation } \\
\text { medium }\end{array}$} & \multirow[b]{2}{*}{ Addition(s) to sporulation medium } & \multicolumn{4}{|c|}{ Percentage of spores $>45 \mu \mathrm{m}^{3}$ by $6 \mathrm{~h}$} \\
\hline & & $\begin{array}{l}\text { MGM/ } \\
\text { glutamate } \\
(100 \mathrm{mM})\end{array}$ & $\begin{array}{l}\text { MGM/ } \\
\text { cellobiose } \\
(50 \mathrm{mM})\end{array}$ & $\begin{array}{c}\text { MGM/ } \\
\text { 3-O-methylglucose } \\
(20 \mathrm{~mm})\end{array}$ & $\begin{array}{l}\text { MGM/ } \\
\text { glucose } \\
(100 \mathrm{~mm})\end{array}$ \\
\hline MSM & None & $<5$ & $<5$ & $<5$ & $>95$ \\
\hline MSM & Peptone* $(1 \%)$ & $<5$ & $<5$ & 36 & $>95$ \\
\hline MSM & Yeast extract $(0.3 \%)$ & 19 & 14 & 57 & $>95$ \\
\hline MSM & $\begin{array}{l}\text { Peptone }(1 \%) \\
\text { Yeast extract }(0.3 \%)\end{array}$ & 48 & 41 & 62 & $>95$ \\
\hline CSM & None & 57 & 41 & 62 & $>95$ \\
\hline MSM & Casamino acids, vitamin-free ( $1 \%)$ & 20 & 16 & 49 & $>95$ \\
\hline
\end{tabular}

source (Fig. 4). However, the combination of 3-O-methylglucose and one of several carbon sources led to the germination of more than $95 \%$ of both C- and M-spores (Table 2).

It was reported (Larsen \& Sypherd, 1974) that a significant rise in intracellular cyclic AMP occurs during spore germination. An explanation of why $\mathbf{M}$-spores do not germinate on non-hexoses could lie in the inability of the sporangiospore to increase intracellular cyclic AMP levels in the absence of glucose and thus its inability to initiate germination. To examine this possibility we added cyclic AMP (10 mM) to $\mathrm{M}$-spores and, as a control, to $\mathrm{C}$-spores in MGM/glutamate. Cyclic AMP did not trigger the germination of $\mathbf{M}$-spores but did stimulate the rate of C-spore swelling (Table 2).

\section{Carbohydrate effect on sporangiospore phenotype}

Glucose is the primary carbon source in MSM. Sporangiospores were produced on either complex or minimal sporulation media in which glucose was replaced by other substrates. When $2 \%$ glucose was replaced by $2 \%(\mathrm{w} / \mathrm{v})$ glutamate or alanine, poor sporulation resulted in both complex and minimal media. These sporangiospores were not tested for their germination ability due to the low number obtained. When glucose was replaced by $2 \%(\mathrm{w} / \mathrm{v})$ galactose, cellobiose, maltose, xylose or ribose, a high level of sporulation resulted, similar to that obtained with glucose. Less than $5 \%$ of the sporangiospores produced on MSM germinated in MGM/glutamate or MGM/cellobiose regardless of whether glucose, galactose, cellobiose, maltose, xylose or ribose was used as the primary carbon source in the MSM. These same sporangiospore preparations all germinated at similar rates $\left(T_{G s 0}=2.3 \mathrm{~h}\right)$ in $\mathrm{MGM} /$ glucose with more than $95 \%$ germinating by $6 \mathrm{~h}$. Replacement of glucose in CSM by another hexose (i.e. galactose) had no effect on the C-spore phenotype.

\section{Effect of nutritional components of the sporulation medium on sporangiospore phenotype}

To examine the effects of the components of CSM on sporangiospore germination ability, the following mixing experiments were performed. Each component of CSM was added singly or in combination to MSM and the subsequent sporangiospore phenotype was tested (Table 3 ). Only the addition of both yeast extract and peptone to MSM resulted in a sporangiospore population equivalent to those produced on CSM.

\section{Effect of yeast extract/peptone (YP) concentration on sporangiospore phenotype}

Sporangiospores were produced on MSM containing the normal $(1 \times)$ YP concentration $(0.3 \%$ yeast extract, $1 \%$ peptone) found in CSM, or $0.01,0.1,2$ or $5 \times$ that concentration. 
Table 4. Effect of yeast extract/peptone $(Y P)$ concentration on sporangiospore germination

\begin{tabular}{|c|c|c|c|c|}
\hline \multirow{2}{*}{$\begin{array}{l}\text { YP concn } \\
\text { (relative } \\
\text { to CSM) } \\
\text { in } \mathrm{MSM}\end{array}$} & \multicolumn{4}{|c|}{ Percentage of spores $>45 \mu \mathrm{m}^{3}$ by $8 \mathrm{~h}$} \\
\hline & $\begin{array}{l}\text { MGM/ } \\
\text { glutamate }\end{array}$ & $\begin{array}{l}\text { MGM/ } \\
\text { cellobiose }\end{array}$ & $\begin{array}{c}\text { MGM/ } \\
\text { 3-O-methylglucose }\end{array}$ & $\begin{array}{l}\text { MGM/ } \\
\text { glucose }\end{array}$ \\
\hline None (MSM) & $3(\text { S.E. } 5)^{*}$ & 4 (S.E. 5) & 2 (S.E. 5) & $>95(2.2) \dagger$ \\
\hline $0.01 \times$ & 5 (S.E. 6) & 8 (s.E. 6) & 17 (s.E. 16) & $>95(1.9)$ \\
\hline $0.1 \times$ & 6 (s.E. 1) & 7 (s.E. 7) & 17 (s.E. 8) & $>95(1.8)$ \\
\hline $1 \times($ normal $)$ & 74 (s.E. 13) & 21 (s.E. 2) & 65 (S.E. 1) & $>95(1 \cdot 7)$ \\
\hline $2 \times$ & 64 (s.E. 4) & 44 (S.E. 11) & 46 (s.E. 9) & $>95(2.4)$ \\
\hline $5 \times$ & 41 (s.E. 6) & 49 (S.E. 10) & 40 (s.E. 10) & $>95(3.2)$ \\
\hline
\end{tabular}

* Standard error of the mean (S.E.); average of two experiments, three replicates per experiment.

$+T_{G 50}$, i.e. calculated (linear regression analysis) time in hours for $50 \%$ of a sporangiospore population to swell from 20 to $>45 \mu^{3}$.

As shown in Table 4, sporangiospores produced on MSM or on MSM supplemented with $0.01 \times$ YP or $0.1 \times$ YP were unable to initiate germination on MGM containing either glutamate, cellobiose or 3-O-methylglucose. The concentration of the nutritionally complex components was apparently insufficient for the production of the $\mathrm{C}$-spore phenotype. At YP concentrations above normal $(1 \mathrm{x})$, the fraction of sporangiospores initiating germination in MGM/glutamate and MGM/3-O-methylglucose correspondingly decreased, while increased germination occurred in $\mathrm{MGM} /$ cellobiose. Surprisingly, the rate of sporangiospore germination in $\mathrm{MGM} /$ glucose also reflected the concentration of YP present in MSM demonstrated by the correlation between $T_{G S O}$ and YP concentration shown in Table 4: germination rates with different YP concentrations decreased in the order $1 \times>0.1 \times$ $>0.01 \times \gg$ MSM $>2 \times \gg 5 \times$.

\section{Effect of peptone type and lot in CSM on sporangiospore germination}

The portion of a population of $\mathrm{C}$-spores germinating on non-hexose substrates was consistent within experiments but varied considerably from experiment to experiment. The type and lot of peptone used in the CSM influenced the proportion of the sporangiospore population capable of initiating germination in $\mathrm{MGM} /$ glutamate. For example, with Difco peptone lot no. $54219,59 \%$ of C-spores had germinated by $4 \mathrm{~h}$ in MGM/glutamate medium, whereas with lot no. 660308 only $28 \%$ of the spores had germinated by $4 \mathrm{~h}$. Other peptones tested were Difco proteose peptone lot no. 512347 (34\% of the spores germinated by $4 \mathrm{~h}$ ), BBL polypeptone lot no. 8012 (33\%) and several other Difco peptones which gave intermediate results.

\section{DIS C USSION}

The synchrony, reproducibility and rate of germination of a sporangiospore population must be known for the specific conditions under which they are to be studied. In previous studies (Bartnicki-Garcia \& Nickerson, 1962; Borgia \& Sypherd, 1977; Orlowski \& Sypherd, 1978), $M$. racemosus sporangiospores were routinely produced on a nutritionally complex sporulation medium (YPG) with the subsequent germination studies carried out in similar liquid medium. The present studies employing a Coulter counter for monitoring germination demonstrated that complete $(>95 \%)$ and synchronous germination of $\mathrm{C}$-spores (produced on the nutritionally complex sporulation medium) occurs in complex media containing yeast extract and/or peptone, or in a minimal medium containing glucose or mannose. The rate of germination varied with the carbon source(s). In contrast, $\mathrm{C}$-spore germination was found to 
be asynchronous in MGM containing a single non-hexose carbon source, with a proportion of the population remaining ungerminated after several days of incubation. In a sampling of one C-spore batch, $70 \%$ were able to germinate on xylose, but only $54 \%$ on glutamate, and $24 \%$ on cellobiose, with variable proportions germinating on the other non-hexoses (Table 1). These $\mathrm{C}$-spores were not defective as greater than $95 \%$ germinated synchronously by $6 \mathrm{~h}$ on glucose, mannose, yeast extract or peptone.

Sporangiospores produced on a defined minimal sporulation medium (MSM; M-spores) did not germinate on any one carbon source except glucose or mannose, but did germinate on complex substrates. The addition of either yeast extract or peptone to MSM did not significantly increase the portion of sporangiospores capable of germinating on glutamate or cellobiose (Table 3), but when they were added in combination the normal C-spore phenotype was observed. This suggests that MSM does not contain an inhibitor of germination. To our knowledge this is the first report where the nutritional complexity of the sporulation medium has been shown to have a direct influence on the subsequent sporangiospore phenotype in terms of germination ability.

The literature is replete with reports linking the nutritional composition of the culture environment to gene expression in both prokaryotic and eukaryotic cells. O'Connor et al. (1978) have reported that extracellular protease synthesis in Bacillus amyloliquefaciens is directly related to the level of amino acids present in the culture medium. Reid et al. (1980) reported that peptone induces extracellular collagenase synthesis in Vibrio alginolyticus. From these studies it cannot be ruled out that one specific chemical in the CSM is influencing $M$. racemosus sporangiospore phenotype. The observation that both yeast extract and peptone are required in combination, and Casamino acids cannot replace the yeast extract and peptone in CSM, along with the observation that various lot numbers and types of peptone influence the $\mathrm{C}$-spore phenotype, all taken together suggest that the sporulation medium is a dynamic environment closely regulating sporangiophore gene expression. This is further supported by the observation that when glucose is replaced by an equal concentration of an amino acid, or omitted from CSM, a low level of sporulation results.

Additional evidence demonstrating a relationship between sporulation medium and sporangiospore germination ability was obtained from experiments where sporangiospores were produced on MSM supplemented with the normal YP concentration found in CSM or various multiples of that concentration (Table 4). Concentrations of $0.1 \times \mathrm{YP}$ and below resulted in sporangiospores with the $\mathrm{M}$-spore phenotype. The most surprising phenotypic difference between these sporangiospore preparations was manifested in the extremes in the germination rates observed on glucose. Sporangiospores produced on $1 \times Y \mathbf{P}$ germinated almost twice as fast as those produced on $5 \times$ YP. From a practical standpoint these observations demonstrate a need to monitor the germination rate of a given sporangiospore preparation in relationship to the evaluation of biochemical parameters which may be chronologically related to germination.

It has been demonstrated in this study that glucose can initiate germination of both $\mathrm{M}$ - and $\mathrm{C}$-spores. In contrast, essentially no $\mathrm{M}$-spores and only a proportion of a $\mathrm{C}$-spore population can germinate on various non-hexoses. One explanation could be that some $\mathrm{C}$-spores have the machinery necessary to convert certain non-hexoses to glucose or another hypothetical signal molecule. Hence, to initiate germination on cellobiose, a $\mathrm{C}$-spore may only require a $\beta$-glucosidase, but on glutamate, an intact, functional gluconeogenic pathway may be needed.

These studies have led to a better understanding of the germination requirements of $M$. racemosus sporangiospores. The mechanism by which a compound initiates germination in a dormant bacterial endospore has been the subject of numerous hypotheses (Dring \& Gould, 1975; Prasad et al., 1972; Vary, 1978; Woese et al., 1968), but has not been elucidated. By employing a defined minimal medium in these studies we have been able to produce a homogeneous minimal ( $\mathbf{M}$-spores) sporangiospore system which is particularly suited for exploring the mechanism(s) involved in the initiation of fungal spore germination. 


\section{REFERENCES}

Barnes, M. \& Parker, M. S. (1967). Use of the Coulter Counter to measure osmotic effects on the swelling of mould spores during germination. Journal of General Microbiology 49, 287-292.

Barnes, M., Parker, M. S. \& Bradley, T. J. (1966). Particle size analysis and the Coulter Counter. Manufacturing Chemist 37, 47-51.

BARTNICKI-GarCIA, S. (1968). Control of dimorphism in Mucor by hexoses: inhibition of hyphal morphogenesis. Journal of Bacteriology 96, 1586-1594.

Bartnicki-Garcia, S. \& NiCKerson, W. J. (1962). Nutrition, growth, and morphogenesis of Mucor rouxii. Journal of Bacteriology 84, 841-858.

BorgIA, P. \& SYPHERd, P. S. (1977). Control of $\beta$-glucosidase synthesis in Mucor racemosus. Journal of Bacteriology 130, 812-817.

DRING, G. J. \& Gould, G. W. (1975). Electron transport-linked metabolism during germination of Bacillus cereus spores. In Spores VI, pp. 488-494. Edited by P. Gerhardt, R. N. Costilow \& H. L. Sadoff. Washington, D.C.: American Society for Microbiology.

LARSEN, A. D. \& SYPHERD, P. S. (1974). Cyclic adenosine $3^{\prime}, 5^{\prime}$-monophosphate and morphogenesis in Mucor racemosus. Journal of Bacteriology 117 , 432-438.

MANDELS, G. R. (1965). In The Fungi, vol. 1, p. 599. Edited by G. C. Ainsworth \& A. S. Sussman. London: Academic Press.

Mandels, G. R. \& DARBY, R. T. (1953). A rapid cell volume assay for fungitoxicity using fungus spores. Journal of Bacteriology 65, 16-22.

MoONEY, D. T. \& SYPHERD, P. S. (1976). Volatile factors involved in the dimorphism of Mucor racemosus. Journal of Bacteriology 126, 12661270.

O'Connor, R., Elliot, W. H. \& MAY, B. K. (1978).
Modulation of an apparent mRNA pool for extracellular protease in Bacillus amyloliquefaciens. Journal of Bacteriology 136, 24-34.

ORLOWSKI, M. \& SYPHERD, P. S. (1978). Regulation of macromolecular synthesis during hyphal germ tube emergence from Mucor racemosus sporangiospores. Journal of Bacteriology 134, 76-83.

PAZNokAs, J. L. \& SYPHERD, P. S. (1975). Respiratory capacity, cyclic adenosine $3^{\prime}, 5^{\prime}$-monophosphate, and morphogenesis in Mucor racemosus. Journal of Bacteriology 124, 134-139.

Peters, J. \& SYPherd, P. S. (1978). Enrichment of mutants of Mucor racemosus by differential freezekilling. Journal of General Microbiology 105, 77-81.

Prasad, C., Diesterhaft, M. \& Freese, E. (1972). Initiation of spore germination in glycolytic mutants of Bacillus subtilis. Journal of Bacteriology 110, 321-328.

ReID, G. C., Woods, D. R. \& RoBB, F. T. (1980). Peptone induction and rifampin-insensitive collagenase production by Vibrio alginolyticus. Journal of Bacteriology 142, 447-454.

Schulz, B. E., Kraepelin, G. \& Hinkelmann, W. (1974). Factors affecting dimorphism in Mycotypha (Mucorales): a correlation with the fermentation/ respiration equilibrium. Journal of General Microbiology 82, 1-13.

VARY, J. C. (1978). Glucose-initiated germination in Bacillus megaterium spores. In Spores VII, pp. 104-108. Edited by G. Chambliss \& J. C. Vary. Washington, D.C.: American Society for Microbiology.

Woese, C. R., Vary, J. C. \& Halvorson, H. O. (1968). A kinetic model for bacterial spore germination. Proceedings of the National Academy of Sciences of the United States of America 59, 869-875. 